\title{
Self Reported Symptoms Associated with Coffee Consumption among University Students in Nigeria
}

Adekunle Anthony Adegoke

\begin{abstract}
This paper examined the psycho physiological effects of coffee consumption as reported by University students. The relationship between coffee consumption and anxiety was also explored. It was hypothesized that heavy caffeine users would report significantly higher anxiety and more psychophysical symptoms of caffenism more than non-users. A sample size of 447-university students made up of 239 males and 208 females within ages 16-36 years $(M=22.7 ; S D=$ 2.92) participated in the study. All respondents completed an adapted version of STAI forms $Y-1$ and $Y-2$ which measures state-trait anxiety. Analysis of data revealed significant difference between coffee users and non-users on state anxiety. The quantity and frequency of daily coffee consumption were found to be related to the symptoms exhibited on state anxiety. There was no significant sex difference on the frequency and quantity of coffee consumption but a significant age difference in favour of younger respondent was recorded on frequency of coffee consumption. Various symptoms reported by the respondents confirmed the stimulating properties of caffeine.

\section{Background}

In the last four decades, several attempts had been made to examine the psychotropic effects of caffeine on human being. Previous attention had been directed towards its effects on motor responses, visual monitoring (Baker et al, 1972) Nash, 1962) Wakefulness; (Goldstein, et al 1965) tolerance; (Colton et al, 1967). Regina, et al (1974; human performance, motor coordination, judgment and mood (Weiss and Latries (1962).
\end{abstract}


Human cardiac response has been subjectively reported to be affected by caffeine ingestion. Particularly in this direction is its ability to raise arterial blood pressure, pulse rate, and cardiac irregularities evident in bradycardia and tachycardia. The vasodilatory property of this alkaloid had led to studies focusing on effects of caffeine on alertness and cardiac arrhythmia. Insomnia, nervousness, and headache have been reported among coffee users (Harne, 1970). Within the gastrointestinal system, caffeine has the potential to produce nausea, vomiting, diarrhea, epigastric pain, and occasionally, peptic ulcer and hematemesis (Truitt, 1971; Greden, 1974). A significant effort has also been directed on the effect of coffee on Blood pressure; (Freestone and Ramsay, 1982; Periti, et al, 1987; Lane, et al, 1998 Al' absi et al, 1998).

Grollman (1951) pointed out that although ideas become clearer, thought flows more freely and fatigue and drowsiness disappear, caffeine ingestion often leads to inhibition of logical, connected thought, and much effort is required to focus attention on a single object. Grollman (1930) study revealed marked nervousness, slight tremor, and a feeling of anxiety. Small doses of caffeine were without effect on the cardio-vascular system. Larger doses (0.5 to 1.0 gram) caused in most cases, a rise in the oxygen consumption (10 to 35 percent,) slight or no changes in the pulse rate, an increase in the arteriole-venous oxygen difference, and a slight rise in the cardiac output. Gins burg and Weintrailb (1976) have also examined the soporific effect of coffee in patients with senile dementia.

In most parts of the world, coffee is consumed more frequently than any other beverage. Several authors (Winstead, 1976; Nehhg, et al, 1992; Rall, 1980 and AL' Abs, 1998), have corroborated the ability of caffeine to activate the central Nervous system and increase the circulating catecholamines and free fatty acids. It has been claimed (Ritchie, 1970; Truitt, 1971, Goldstein, 1965) that coffee intake promote rapid, clear thinking, improved intellectual effort, enhanced mental acuity and decreased drowsiness, fatigue, and inaction time. 
Tyler (1975) characterized caffeine as a cortical stimulant, which relieves fatigue, increases awareness, decreases appetite, and often becomes moderately addictive. Caffeine has been described as an almost ideal stimulant in that it enhances cognition and motor activity and produces few or no side effects for most people (Thompson, 1975). There is the widespread belief that caffeine enhances mental and psychical performance but experimental support for this belief is neither extensive nor equivocal

In general population, Baker and Theologus (1972) reported that caffeine is taken in many forms to increase "alertness". The premise that caffeine aids alertness seems to have broad acceptance in spite of a relative absence of empirically convincing evidence. This has led to its general consideration as a socially acceptable and relatively benign psychotropic drug despite its ability to produce dependence, tolerance and withdraw symptoms on heavy use (Ritchie, 1970). However, the general public has been reluctant to classify caffeine as a drug. This substance has been domesticated to the extent of its incorporation into our daily life in such rituals as the coffee break and the coffee club (Brecher, 1972).

The clinical literature on psychological and physiological reactions to caffeine and caffeine containing beverages is extensive. As noted earlier, caffeine is not without its side effects. Behavioural effects are partially dependent upon the tolerance level of user, which is increased by chronic usage. Doses that increase tolerance result in indigestion; nervousness and insomnia (Leukel, 1972; Childs, 1978). Of research interest is "Caffeinism" in which high caffeine consumption produced a pattern of physiological and psychological reactions indistinguishable from anxiety neurosis. Greden (1978) has defined caffeinism pharmacologically as the ingestion and consequent actions of high doses of caffeinism, whether from coffee, tea, cola drinks, over-the-counter substances, or prescription medications. Symptoms of caffeinism include nervousness, irritability, agitation 
headache, tachypnea, tremulousness, reflex hyper excitability, and occasional muscle twitching (Ritchie, 1970; Hire, 1978).

The anxiety constellation of caffeinism has long been recognized; the media have aptly described it as coffee nerves. In addition to toxic manifestations of caffeine stimulation, similar clinical complaints can result from a characteristic caffeine withdrawal syndrome. Goldstein and Kaiser (1969) found in a survey among housewives that heavy coffee users described a typical set of dysphoric symptoms if they omitted morning coffee. Symptoms include irritability, inability to work effectively, nervousness, lethargy, and restlessness.

Further research has confirmed a significant relationship between excessive caffeine consumption and high level of self-reported anxiety and depression in hospitalized patients (Winstead, 1976, Greden et al, 1978,). Among College undergraduates, Gilliland and Andress (1981) established a strong relationship between high caffeine consumption and anxiety. The results obtained corroborate some previous findings in this regard (Ritchie, 1970; Hive, 1978; Goldstein et al 1969; Colton, et al 1967; Greden et al 1978; Winstead, 1978; Stillner, et al 1978).

The present investigation was designed to examine the relationship between caffeine consumption, an evidence of psycho physiological symptoms of caffeinism and anxiety among University undergraduates. It is hypothesized that heavy caffeine users would report significantly higher anxiety and more psychophysical disorders and symptoms of caffeinism more than non-users.

\section{Methods}

For the examination of individual differences in anxiety and caffeine consumption 447 university students comprising of 239 males and 208 females within the age of 16 years and 36 years (m. 22.7, S.D. 2.92) participated in this study. The students were asked to fill a set of questionnaire, which is made up of three sections. The first part deals 
with a number of items dealing with coffee consumptions and associated feelings and symptoms observed on ingestion, while the second section measured the anxiety level of the respondents. The Spielberger (1983) version of the State-Trait Anxiety Inventory (STAI) form Y-1, and Y-2 were used to achieve this. Both STAI forms (Y-1 and Y-2) were modified version of the STAI series, developed to measure state and trait anxiety which is momentary of transitory or situation specific emotion, characterised by feelings of tension, apprehension, and automatic arousal. Each of the forms has 20 items designed to measure different aspects of anxiety as a characteristic of personality. The STAI has been adapted for the use of professionals in Nigeria after several years of research at restandardising it in order to enhance its suitability and relevance for Nigerians. For Nigerian samples, it has a reliability coefficient of 0.61 for test -retest at two weeks interval and high concurrent validity of 0.69 with Zuckerman and Lubin (1965) MAACL (anxiety) Scale. The last part of the questionnaire assessed the occurrence of side effects in areas of mood, tension, sleep disturbance, intellectual functioning, and general somatic (muscular/sensory) cardiovascular, respiratory and autonomic systems. A "symptom experience" score was obtained by summing a subject's responses indicating an increase in a symptom. Subjects responded by checking the appropriate response on two different response formats; yes/no and 3 - point scale ranging from "Never" to "always". . Of the total 424 data found analysable, 248 were coffee users while the remaining 176 subjects were non-coffee users. These two categories were so designated as users and nonusers in most of the analyses.

\section{Procedure}

The respondents were questioned regarding the number of cups of coffee they drank per day, and they were classified into four groups; no coffee, 1-2 cups, 3-4 cups and 5 or more cups. A non-coffee user was one who, by his own estimation, usually drank no more than one cup of coffee or tea or bottle of cola beverage per day; all others are described as "coffee users". The frequency of coffee consumption was 
also ascertained. Coffee users indicated the frequency of their coffee consumption in this order, daily, 2-3 times weekly and occasionally. The mean, standard deviation and median scores of these categories of users on quantity and frequency of coffee consumption on state-trait anxiety were presented in Table 1 . We hypothesised that coffee users would report significant higher anxiety level and more psychological symptoms of caffeine than non-coffee users.

\section{Results}

Descriptive analysis on reasons for consuming coffee varied. Sixty five percent of coffee users indicated likeness for its taste while about fifty-three percent find it enjoyable to drink. Only twenty - four percent felt the need for it, while only eighteen per cent had cultivated the habit of coffee consumption. Seventeen per cent of coffee users recognised the relaxation ability of coffee while an insignificant three percent noticed the depressed activity of coffee as they confessed that it slows one down. The influence of friends was also found to be insignificant. Only seven percent of all coffee users indicated that their friends lured them into coffee consumption.

On the stimulating properties of coffee consumption, of all the users, fifty two percent of acknowledged the stimulating ability of coffee together with forty-eight percent indicating coffee power to wake one up. Twenty-eight percent testified to coffee's energy yielding ability, about 21 per cent noticed the feeling of well being and another thirty percent admitted that coffee gets one going in the morning. There were some noticeable behavioural changes noticed among coffee users after drinking morning coffee and were reported here in the order with which they were found most prominent among the subjects. They include "becoming more alert (79.4\%), become more active (77.5\%), work more efficiently (73.8\%), become more relaxed (42.2\%), "perking" (38.6\%), less irritable (25.9\%). The least noticeable symptoms include nervousness, less efficient (10.1\%), drowsiness $(8.0 \%)$ and sluggishness $(4.8 \%)$. Similarly, coffee users noticed that whenever they drank coffee, they tend to have these stimulatory properties of caffeine arranged in descending order; decreased 
Adekunle Anthony Adegoke.

drowsiness (61.6\%), rapid clear thinking (53.3\%), less fatigue $(52.4 \%)$, disturbed sleep (52\%), enhanced mental acuity $(51.9 \%)$ and improved intellectual ability $(46.6 \%)$.

Symptoms characteristics of negative effects of coffee consumption were less noticeably among coffee users, the most reported were: fast breathing (15.2\%), palpitation (14.5\%), loss of appetite $(26.8 \%)$, stomach irritation $(11.0 \%)$ and diarrhoea (5.9\%). Of these 248 coffee users, forty-one percent experienced nervousness occasionally, fiftytwo percent reported occasional restlessness, and about forty-one percent noticed headache occasionally. Among these users, twenty seven percent occasionally felt agitated, while about $19 \%$ experienced tremor of lower limbs. Another 30\% reported occasional muscle twitching. All these symptoms revealed elements of caffeine withdrawal among coffee users. If they however missed their daily coffee consumption, coffee users reported these symptoms; inability to work effectively (86.5\%), not active (78.4\%), not become alert $(79.2 \%)$ and not be energetic $(77.7 \%)$, not fully awake $(85.5 \%)$. Only few coffee users noticed headache (7.8\%), irritability $(8.9 \%)$, nervousness $(5.5 \%)$, restlessness $(14.7 \%)$, and would become lethargic $(4.9 \%)$ if they miss daily coffee consumptions. When cross tabulated against the frequency of consumption the following symptoms were observed to be significant improved intellectual ability; enhanced mental acuity, rapid clear thinking, less fatigue, becoming more active, working efficiently, alertness, sleeping patterns, restlessness, nervousness, becoming irritable, headache and fast breathing. Feelings of agitation, tremor, and occasional muscle twitching were however found not to be influenced by the frequency of coffee consumption. (See table 2)

Table 3 and 4 showed the result on the difference between users and non-coffee users on state and trait anxiety. It was shown that coffee users had significant state anxiety more than non-users $[\mathrm{t}(341)=3.40$; $\mathrm{P} \leq 0.001]$. Scores of users were found to be higher on state anxiety more than non-coffee users $(m=45.63, S . D=8.09)$ with a mean difference of $(\mathrm{m}=48.83, \mathrm{~S} . \mathrm{D}=9.05) 3.20$. The difference between 
Self Reported Symptoms Associated with Coffee Consumption...

users and non-users on trait anxiety were not statistically significant [ $\mathrm{t}$ $(337)=1.32 ; \mathrm{P}>0.05]$, thus confirming non significant influence of coffee consumption on trait anxiety.

The quantity of daily coffee consumption were also found to be related to the symptoms exhibited on state anxiety $(\mathrm{F}(3,290)=4.724$; $\mathrm{P} \leq 0.003)$ Scheffe and LSD post hoc tests revealed significant difference between those who consumed 1-2 cups of coffee daily and none coffee users. There is also a difference between those with 34 cups daily consumption and non-coffee users. Quantity of daily coffee consumption however did not make any significant influence on trait anxiety $(\mathrm{F}(3,281)=1.259 ; \mathrm{P}>0.05)$. This is shown in Table 5 .

On the frequency of coffee consumption and anxiety state, the result on Table 6 revealed a significant influence of frequency of consumption on both state and trait anxiety. [State: $F(3,188)=2.681$; $\mathrm{P}<0.05]$; trait: $\mathrm{F}(3,183=2.787 ; \mathrm{P}<0.05)$. Schefe and LSD post hoc tests showed a significant difference on state anxiety for those with weekly coffee consumption and occasional drinkers $(\mathrm{M} . \mathrm{D}=4.77 ; \mathrm{P} \leq$ 0.027). This difference becomes clearer on trait anxiety as those with daily consumption were found to differ from those who consume coffee on weekly basis. So also is the difference between weekly drinkers and occasional drinkers of coffee (M.D. $=-5.76 ; \mathrm{P} \leq 0.030$ ).

The study also found a positive significant relationship between symptoms experienced by coffee user and both levels (state and trait) of anxiety. (State, 0.18; $\mathrm{P} \leq 0.042$; trait $\mathrm{r}=0.207$ : $\mathrm{P} \leq 0.020$ ). Symptoms experienced were: influenced more by the frequency of coffee consumption than the quantity (number of cups) consumed daily $(F(3,134)=6.86 ; \mathrm{P} \leq 0.000)$. Scheffe post hoc test revealed a significant mean difference of $6.72, \mathrm{P} \leq 0.023$ between symptoms experienced by daily users of coffee and occasional users. (See Table 8). Significant differences were also found in the symptoms experienced by occasional users and those with 2-3 times weekly. (M.D. = 9.16, $\mathrm{P} \leq 0.001)$. Although quantity consumed daily had no significant influence on the symptoms experienced generally, it was 
however discovered that when morning coffee was missed, symptoms experienced were both influenced by the quantity and frequency of coffee consumption [quantity: $\mathrm{F}[3,239)=3.98 ; \mathrm{P} \leq 0.008$ ], [frequency: $\mathrm{F}(3,201)=2.765 ; \mathrm{P} \leq 0.043$ ]. (See Table 7)

In addition, there were notable differences in responses to trait items of the STAI (which asses how one generally feels). High and moderate consumers obtained significantly higher mean and median scores, indicating significantly greater levels of trait anxiety (See table 1). When we evaluated state scale items from the STAI (which measure how one feels at the moment), the observed similar patterns; total mean and median scores on the state scale were again significantly higher for the highest consumers (See table 1).

It was also discovered that quantity (no. of cups) of coffee consumed daily had effect on being nervous, tremor experience restless and feelings of agitation but not related to other symptoms. The higher the number of cups of coffee consumed, the more noticeable were these symptoms. Table 9 has the results on Quantity of daily consumption and reported symptoms.

Examination of sex difference showed a higher number of coffee consumers to be males (147), compared with the females (100), and there was no significant difference in their frequency of coffee consumption $\left(\mathrm{x}^{2}=1.3777\right.$; $\left.\mathrm{df}=3, \mathrm{P} \geq 0.711\right)$.

On age comparison on coffee consumption, respondents in the age bracket (16 - 20 years) consumed coffee more frequently (Daily and 2 -3 times weekly) than 21-36 year old group $\left(\mathrm{x}^{2}=9.420 ; \mathrm{df}=3 ; \mathrm{P} \leq\right.$ 0.024). There was however no significant difference between age group $(16-20$ years) and $(21-26$ year) on quantity (number of cup of coffee) consumed daily $\left(\mathrm{x}^{2}=6.337 ; \mathrm{df}=3 ; \mathrm{P} \geq-0.96\right)$.

\section{Discussion}

The main finding that emerges from this study was that coffee users differ from non-coffee users in a number of significant ways. They 
tend to be somewhat older, possibly because their habit has taken some years to develop. The recorded age difference were however only significant for frequency of coffee consumptions and not quantity consumed daily. This result on age difference is however inconsistent with Gilland and Andress (1981) study in which age yielded no significant effect for quantity of coffee consumption. There was no significant sex difference neither in the quantity nor frequency of coffee consumption. The only notable sex difference was in the number of coffee users, in which makes outnumbered the females.

The most striking observable trends were the symptoms experienced in relation to the frequency of coffee consumption. Almost all the symptoms identified namely: improved intellectual ability, enhanced mental acuity, rapid clear thinking, less fatigue, becoming more active, working efficiently, alertness, sleeping patterns, restlessness, nervousness, becoming irritable, headache and fast breathing were significantly related to and varied the frequency of coffee consumption. The purely caffeine withdrawal symptoms; restlessness, Nervousness and feelings of agitation were however significant for quantity of daily coffee consumption. Reasons for taking coffee are generally the same as given by light users: That coffee is an enjoyable, pleasant tasting beverage that helps one wake up and get going.

In addition, a greater proportion of them acknowledged "likeness for the taste" and the importance of a feeling of well being and a certain "lift" produced by morning coffee. The behavioural changes attributed to coffee consumption are the same in all coffee - users; make one alert, more active, perk up, and are more common depending on the frequency of coffee consumption. These symptoms are consistent and in line with previous studies in this direction (Goldstein and Kaizer, 1969; Colton, et. al., 1968). On the other hand, moderate and heavy users present a constellation of dysphoric symptoms (restlessness, nervousness, irritability, headache, feelings of agitation), which are features of caffeine withdrawal syndrome. The evidence showing that there are psycho stimulant effects of caffeine as 
reported by subjects in this study corroborates other previous findings (Ritchie, 1970, Truitt, 1971, Goldstein, 1965; Hire, 1978, Lynn, 1973).

The results gave credence to the importance of the factors mentioned in Thompson (1975) and Theologus (1972) studies that caffeine enhances mental and psychical performance and also promotes alertness. There was a significant difference between coffee users and non-users on state anxiety. High coffee users, therefore in addition to reporting more psycho physiological symptoms, reported more features of state anxiety. This is similar to Greeden, et al. (1978) findings. The finding on elevated anxiety symptoms among coffee users was somewhat expected because of caffeine's known pharmacological actions. Not only is caffeine itself a central nervous system stimulant, it also secondarily increases catecholamine output, which certainly contributes to the anxiety profile (Bellet, et. al., 1969; Lev., 1967). This finding also corroborated Winstead (1976) study among psychiatric in patients in which anxiety inventory revealed a statistically significant elevation in state anxiety for the high-users group.

The results of this study are comparable to the questionnaire data reported by Goldstein and Kaizer (1969). In a survey of 239 house wives, they found heavy users reporting more symptoms of caffeine withdrawal, such as nervousness, irritability and restlessness, a group of symptoms which in the present study found more related to quantity of daily coffee consumption. Quantity of coffee consumed daily had effect on nervousness, restless and feelings of agitation. The higher the number of cups of coffee consumed, the more noticeable were these symptoms. The results reported here again supported and extended the findings of Leukel (1978), Ritche, 1970, Hire, 1978 and Greden (1978) which revealed symptoms of Caffeinism. The relationship between exhibition of these symptoms and quantity of coffee consumption are not mere coincidence, the symptoms are behavioural effects of caffeine consumption, which are partially 
dependent upon the tolerance level of user, which is increased by chronic usage.

\section{Conclusion}

The findings from the study have corroborated various previous works on the psycho physiological symptoms of Caffeimsm and anxiety commonly associated with coffee consumption. It is evident from selfreported symptoms that coffee consumption stimulates human cardiac response and capable of producing certain psychopathological disorders linked with state anxiety. It is thus concluded that quantity and frequency of coffee consumption had significant effect on the state anxiety level.

\section{References}

Al' Absi, M; Lovallo, W.R.: Mckey, B; Sung, B.E: Whitset, T.L. and Wilson, M.F. (1998): "Hypothalamic - Pituitary - Adrenocortical Responses to Psychological Stress and Caffeine in Men at High and Low Risk for Hypertension." Psychosomatic Medicine 60: 521 527.

Baker, W.J. and Theologus, G.C. (1972): "Effects of Caffeine on Visual Monitoring." Journal of Applied Psychology_Vol. 56(5), 422 - 427.

Barone, J.J. and Roberts, H.R. (1996): "Caffeine Consumption." Food Chemistry and Toxicology, Vol. 34 (1); 119 - 129.

Brecher, E.M. (1972): Licit and Illicit Drugs. Boston. Little Brown and Co. $193-206$.

Bellet, S.;Roman, L., Decastro, O. et. al. (1969): "Effect of Coffee Ingeston on Catecholamien Release". Metabolism, 18: 288 - 291.

Childs, M.M. (1978): "Caffeine Consumption and Target Scanning Performance." Human Factors, 20(1); 91 - 96.

Colton, T.; Gosselin, R.E. and Smith, R.P. (1967): “The Tolerance of Coffee Drinkers to Caffeine." Clinical Pharmacology and Therapeutics, Vol. 9(1); 31-39.

Elkings, R.N.; Rapoport, J.L., Zahn, T.P., Buchsbaum, M.S.; Weingartner, H., Kopin, I.J., Langer, D. and Johnson, C. (1981): “Acute Effects of Caffeine in Normal Prepubertal Boys." American Journal of Psychiatry 138 (2): 178 - 183. 
Freestone, S. and Rainsay, L.E. (1982): "Effect of Coffee and Cigarette Smoking on the Blood Pessure of Untreated and Diuretic - Treated Hypertensive Patients." The American Journal of Medicine, Vol. $173 ; 348$.

Gilliland, K. and Andress, D. (1980): "Ad Lib Caffeine Consumption, Symptoms of Caffeinism and Academic Performance." American Journal of Psychiatry 138 (4); 512-514.

Ginsbury, R. and Weintraub, M. (1976): "Caffeine in the 'Sundown Syndrome"”. Journal of Gerontology. Vol. 31(4); $419-420$.

Goldstein, A.; Warren, R. and Kaizer, S. (1965): "Psychotropic Effects of Caffeine in Man I. Individual Differences in Sensitivity to Caffeine Induced Wakefulness." The Journal of Pharmacology and Experimental

Goldstein, A. and Kaizer, S. (1969): "Psychotropic Effects of Caffeine in Man. III. A Questionnaire Survey of Coffee Drinking and its Effects in a Group of Housewives." Clinical Pharmacology and Therapeutics. 10(4); 477-488.

Greden, J.F. (1974): "Anxiety or Caffeinism: A Diagnostic Dilemma." American Journal of Psychiatry 131; 1089 - 1092.

Greden, J.F.; Fontaine, P.; Lubetsky, M. and Chamberlin, K. (1978): "Anxiety and Depression Association with Caffeinism among Psychiatric in Patients". American Journal of Psychiatry 135(8): $963-966$.

Grollman, A. (1930): "The Action of Alcohol, Caffeine, and Tobacco on the Cardiac Output (and its related functions) of normal man." Journal of Pharmacology and Experimental Therapeutics. 39: 313 - 327.

Grollman, A. (1950): Pharmacology and Therapeutics. Philadelpha: Lea and Febiger.

Hemminski, E.; Rahkonen, O; Rimpela, A. and Rimpela M. (1988). "Coffee Drinking among Finnish Youth." Social Science and Medicine, Vol. 26 (2); 259 - 264.

Hire, J.N. (1978): “Anxiety and Caffeine.” Psychological Reports. 42; 833 -834 .

Karacan, I. Thornby, J.I.; Anch, M; Booth, G.H.; Williams, R.L. and Salis, P.J. (1976). "Dose-related Sleep Disturbances Induced by Coffee and Caffeine." Clinical Pharmacology and Therapeutics. Vol. 20(6), $682-689$.

Lane, J.O. Phillips-Bute, B.G. and Pieper, C.F. (1998): "Caffeine Raises Blood Pressure at Work." Psychosomatic Medicine 60: 327 - 330. 
Self Reported Symptoms Associated with Coffee Consumption...

Leukel, F. (1972): Introduction to Physiological Psychology. Saint Louis: CV Mosby.

Levi, L. (1967): "Effect of Coffee on the Function of the Sympathoadveno Medullary System in Man." Acta Medical Scandinavian; 181: 431438.

Lynn, R. (1973): "National Differences in Anxiety and the Consumption of Caffeine." British Journal of Social and Clinical Psychology, 12; $92-93$.

Nash, H. (1962): Alcohol and Caffeine. Spring Field. Charles C. Thomas.

Nehlig, A; Daval, J.L. Debry, G. (1992): "Caffeine and Central Nervous System: Mechanisms of Action, Biochemical, Metabolic and Psychostimulant Effects." Brain Research and Review 17: 139 170.

Periti, M; Salvaggio, A; Quaglia, Gland Marzio, L.D. (1987): "Coffee Consumption and Blood Pressure: An Halian Study." Clinical Science, $72 ; 443-447$.

Rall, T.W. (1980): "Central Nervous System Stimulants: The Xanthines." In: Goodman L.S. and Gilman, A.G. (Eds.) Pharmacological Basis of Therapewtics, 6th Edition. New York, Macmillan; 589 - 603.

Regina, E.G.; Smith, G.M., Keiper, C.G. and Mckelvy, R.L. (1974): "Effects of Caffeine on Alertness in Simulated Automobile Driving." Journal of Applied Psychology, 59, 483 - 489.

Ritche, J.M. (1970): "Central Nervous System Stimulants II: The Xanthines." In L.S. Goodman \& A. Gilman (Eds). The Pharmacological Basis of Therapeutics (4 ${ }^{\text {th }}$ Ed.) New York: Macmillan pp. 358 - 370.

Speilberger, C.D.; Gorsuch, R.L. and Lushene, R.E. (1970): State-Trait Anxiety Inventory Manual. Palo Alto, California, Consulting Psychologists Press.

Stillner, V; Popkin, M.K. and Pierce, C.M. (1978): "Caffeine-induced Delirium During Prolonged Competitive Stress." American Journal of Psychiatry. 135(7); $855-856$.

Thompson, R.F. (1975): Introduction to Physiological Psychology. New York: Harper and Row.

Truitt, E.B. (1971): "The Xanthines." In Drill's Pharmacology in Medicine" (4th ed) New York: McGraw-Hill Pp. 533 - 556.

Teyler, T.J. (1975): A Primer of Psychology: Brain and Behaviour. San Francisco, Freeman. 
Weiss, B. and Laties, V.G. (1962): "Enhancement of Human Performance by Caffeine and the Amphetamines." Pharmacological Review, 14; $1-36$.

Winstead, D.K. (1976): "Coffee Consumption among Psychiatric Inpatients." American Journal of Psychiatry, 133 (12); 1447 - 50.

Table 1: Variability of Respondents on State-Traits Anxiety Inventory

\begin{tabular}{|c|c|c|c|c|c|c|c|c|c|}
\hline & & Scal & & & & & & & \\
\hline & Levels & $\operatorname{Trc}$ & Items & & & Sta & Item & & \\
\hline. & & $\mathrm{N}$ & Mean & Std & Median & $\mathrm{N}$ & Mean & Std & Median \\
\hline$\vec{\Xi}$ & None & 93 & 44.53 & 9.09 & 44 & 98 & 45.02 & 8.27 & 46 \\
\hline 0 & 1-2 Cups & 177 & 45.57 & 7.61 & 45 & 180 & 48.83 & 9.16 & 48 \\
\hline 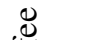 & 3-4 Cup & 11 & 48.18 & 5.12 & 46 & 11 & 50.55 & 5.32 & 50 \\
\hline$e_{i}^{0}$ & $\begin{array}{l}5 \text { or more } \\
\text { Cups }\end{array}$ & 4 & 50.00 & 8.52 & 50 & 5 & 51.4 & 9.34 & 49 \\
\hline อ̆ & Total & 285 & 45.39 & 8.08 & 45 & 294 & 47.67 & 8.93 & 47 \\
\hline & Daily & 43 & 46.00 & 7.23 & 47 & 44 & 48.73 & 9.45 & 48.5 \\
\hline ن & $\begin{array}{l}2-3 \text { times per } \\
\text { week }\end{array}$ & 41 & 46.17 & 6.62 & 47 & 43 & 48.14 & 7.23 & 48 \\
\hline $0 \approx$ & Weekly & 20 & 50.00 & 7.9 & 48 & 21 & 52.14 & 12.60 & 48 \\
\hline 兰 & Occasionally & 107 & 44.23 & 8.46 & 44 & 110 & 47.37 & 8.58 & 47 \\
\hline 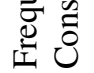 & Total & 211 & 45.52 & 7.97 & 46 & 218 & 48.26 & 9.01 & 48 \\
\hline
\end{tabular}


Table 2: Frequency of Coffee Consumption on Self Reported Symptoms

\begin{tabular}{|l|l|l|l|}
\hline \multicolumn{1}{|c|}{ Item } & \multicolumn{1}{|c|}{$\mathbf{x}^{2}$-value } & df & P-value \\
\hline Improved intellectual ability & 39.17 & 3 & $0.0001^{*}$ \\
\hline Enhanced mental acuity & 29.86 & 3 & $0.0001^{*}$ \\
\hline Rapid clear thinking & 47.91 & 6 & $0.0001^{*}$ \\
\hline Less fatigue & 22.18 & 3 & $0.0001^{*}$ \\
\hline Becoming more active & 24.91 & 6 & $0.002^{*}$ \\
\hline Working efficiently & 29.56 & 3 & $0.0001^{*}$ \\
\hline Alertness & 20.36 & 6 & $0.002^{*}$ \\
\hline Sleeping patterns & 42.42 & 6 & $0.0001^{*}$ \\
\hline Restlessness & 29.31 & 6 & $0.001^{*}$ \\
\hline Nervousness & 14.54 & 6 & $0.02^{*}$ \\
\hline Becoming irritable & 27.90 & 6 & $0.0001^{*}$ \\
\hline Feelings of agitation & 8.62 & 6 & 0.19 \\
\hline Headache & 14.20 & 6 & $0.03^{*}$ \\
\hline Hand shaking (tremor) & 10.08 & 6 & 0.12 \\
\hline Occasional Muscle Twitching & 10.41 & 0.11 \\
\hline Breathing becoming faster & 17.84 & $0.0001^{*}$ \\
\hline$*$ Statistically significant at P $\leq 0.05$ & & \\
\hline
\end{tabular}

* Statistically significant at $P \leq 0.05$ 
Table 3: T-test Comparison of Coffee Users and Non-coffee Users on State-Anxiety

\begin{tabular}{|c|c|c|c|c|c|c|c|}
\hline Group & $\mathrm{N}$ & Mean & $\begin{array}{l}\text { Std } \\
\text { Dev. }\end{array}$ & Tval & df & $\begin{array}{c}\text { Sig. } \\
(2- \\
\text { tailed) }\end{array}$ & $\begin{array}{c}\text { Mean } \\
\text { Diff }\end{array}$ \\
\hline \multirow[t]{2}{*}{ Coffee users } & 194 & 48.83 & 9.05 & & & & \\
\hline & & & & $3.40^{*}$ & 341 & 0.001 & 3.20 \\
\hline $\begin{array}{l}\text { Non-Coffee } \\
\text { Users }\end{array}$ & 149 & 45.63 & 8.09 & & & & \\
\hline Total & 343 & & & & & & \\
\hline
\end{tabular}

*Statistically significant, $\mathrm{P}<0.001$

Table 4: T-test Comparison of Coffee Users and Non-Users on Trait-Anxiety

\begin{tabular}{|c|c|c|c|c|c|c|c|}
\hline Group & $\mathrm{N}$ & Mean & $\begin{array}{c}\text { Std } \\
\text { Dev. }\end{array}$ & Tval & df & $\begin{array}{l}\text { Sig. } \\
(2- \\
\text { tailed) }\end{array}$ & $\begin{array}{c}\text { Mean } \\
\text { Diff }\end{array}$ \\
\hline \multirow[t]{2}{*}{ Coffee users } & 190 & 45.65 & 7.62 & & & & \\
\hline & & & & 1.32 & 337 & 0.187 & 1.13 \\
\hline $\begin{array}{l}\text { Non-Coffee } \\
\text { Users }\end{array}$ & 149 & 44.52 & 8.02 & & & & \\
\hline Total & 339 & & & & & & \\
\hline
\end{tabular}

- Not statistically significant. $\mathrm{P}>0.05$ 
Table 5:One-way ANOVA of the Quantity of Daily Coffee Consumption on State- Trait Anxiety

\begin{tabular}{|ll|l|l|l|l|l|}
\hline & $\begin{array}{c}\text { Sum of } \\
\text { Squares. }\end{array}$ & df & $\begin{array}{c}\text { Mean } \\
\text { Square }\end{array}$ & F & Sig. \\
\hline STATE & Between Groups & 1089.786 & 3 & 363.262 & 4.724 & $.003^{*}$ \\
& Within Groups & 22301.548 & 290 & 76.902 & & \\
& Total & 23391.333 & 293 & & & \\
& Between Groups & 245.800 & 3 & 81.933 & 1.259 & .289 \\
& Within Groups & 18282.186 & 281 & 65.061 & & \\
& Total & 18527.986 & 284 & & & \\
\hline
\end{tabular}

Table 6: One-way ANOVA of Frequency of Coffee Consumption on State- Trait Anxiety

\begin{tabular}{|ll|l|l|l|l|l|}
\hline & $\begin{array}{c}\text { Sum of } \\
\text { Squares. }\end{array}$ & \multicolumn{1}{|c|}{ df } & $\begin{array}{c}\text { Mean } \\
\text { Square }\end{array}$ & F & Sig. \\
\hline STATE & Between Groups & 648.130 & 3 & 216.043 & 2.681 & $.048^{*}$ \\
& Within Groups & 15147.198 & 188 & 80.570 & & \\
& Total & 15795.328 & 191 & & & \\
\hline TRAIT & Between Groups & 476.228 & 3 & 158.743 & 2.787 & \\
& Within Groups & 10422.179 & 183 & 56.952 & & \\
& Total & 10898.406 & 186 & & & \\
\hline
\end{tabular}


Adekunle Anthony Adegoke.

Table 7: One Way Analysis of Variance 0n the Influence of Quantity and Frequency of Coffee Consumption on Symptoms Experienced If Users Missed Morning Coffee

\begin{tabular}{|c|c|c|c|c|c|c|}
\hline & & $\begin{array}{l}\text { Sum of } \\
\text { Squares }\end{array}$ & Df & $\begin{array}{l}\text { Mean } \\
\text { Square }\end{array}$ & $\mathrm{F}$ & Sig. \\
\hline \multirow[t]{3}{*}{ Quantity } & $\begin{array}{l}\text { Between } \\
\text { Group }\end{array}$ & 296.954 & 3 & 98.985 & 3.981 & $.009 *$ \\
\hline & $\begin{array}{l}\text { Within } \\
\text { Groups }\end{array}$ & 5942.832 & 239 & \multirow[t]{2}{*}{24.865} & & \\
\hline & Total & 6239.786 & 242 & & & \\
\hline \multirow[t]{3}{*}{ Frequency } & $\begin{array}{l}\text { Between } \\
\text { Groups }\end{array}$ & 181.752 & 3 & 60.584 & 2.765 & $.043 *$ \\
\hline & $\begin{array}{l}\text { Within } \\
\text { Groups }\end{array}$ & 4404.472 & 201 & \multirow[t]{2}{*}{21.913} & & \\
\hline & Total & 4586.224 & 204 & & & \\
\hline
\end{tabular}

* Statistically significant; $\mathrm{P} \leq 0.05$ 
Self Reported Symptoms Associated with Coffee Consumption...

Table 8: $\quad$ One Way Analysis of Variance on the Influence of Quantity and Frequency of Coffee Consumption on Symptoms Experienced by Coffee Users

\begin{tabular}{|c|c|c|c|c|c|c|}
\hline & & $\begin{array}{l}\text { Sum of } \\
\text { squares }\end{array}$ & Df & $\begin{array}{l}\text { Mean } \\
\text { square }\end{array}$ & $\mathrm{F}$ & Sig. \\
\hline \multirow[t]{3}{*}{ Quantity } & $\begin{array}{l}\text { Between } \\
\text { Group }\end{array}$ & 1950.039 & 3 & 650.013 & 6.856 & .000 \\
\hline & $\begin{array}{l}\text { Within } \\
\text { Groups }\end{array}$ & 12705.061 & 134 & \multirow[t]{2}{*}{94.814} & & \\
\hline & Total & 14655.100 & 137 & & & \\
\hline \multirow[t]{3}{*}{ Frequency } & $\begin{array}{l}\text { Between } \\
\text { Groups }\end{array}$ & 248.923 & 3 & 82.974 & .760 & .519 \\
\hline & $\begin{array}{l}\text { Within } \\
\text { Groups }\end{array}$ & 14748.308 & 135 & \multirow[t]{2}{*}{109.247} & & \\
\hline & Total & 14997.232 & 138 & & & \\
\hline
\end{tabular}

* Statistically significant at $\mathrm{P} \leq 0.05$ level of significance. 
Table 9: Relationship Between Quantity (No of cups) of Daily coffee Consumption and Self Reported Symptoms

\begin{tabular}{|l|l|l|l|}
\hline Item & $\mathrm{X}^{2}$-value & $\mathrm{df}$ & P-value \\
\hline Improved intellectual ability & 4.61 & 9 & 0.87 \\
\hline Enhanced mental acuity & 0.24 & 3 & 0.97 \\
\hline Rapid clear thinking & 3.94 & 3 & 0.69 \\
\hline Fatigue & 0.54 & 3 & 0.911 \\
\hline Sleeping patterns & 2.80 & 3 & 0.42 \\
\hline Restlessness & 16.78 & 6 & $0.01^{*}$ \\
\hline Nervousness & 21.59 & 6 & $0.001^{*}$ \\
\hline Drowsiness & 5.69 & 3 & 0.13 \\
\hline Palpitations & 2.59 & 3 & 0.46 \\
\hline Breathing becoming faster & 0.39 & 3 & 0.94 \\
\hline Feeling of Agitation & 13.38 & 6 & $0.04^{*}$ \\
\hline Hand shaking (tremor) & 5.54 & 6 & $0.04^{*}$ \\
\hline Occasional muscle twitching & 3.33 & 0.37 \\
\hline Headache & & 6 & \\
\hline
\end{tabular}

